\title{
Modeling Energy Use and Emissions from North American Shipping: an Application of Ship Traffic, Energy and Environment Model
}

\section{(Supporting Information)}

\author{
Chengfeng Wang, James J. Corbett ${ }^{*}$, Jeremy Firestone
}

College of Marine and Earth Studies, University of Delaware, Robinson Hall, Newark, DE 19716 chengfengwang@gmail.com; jcorbett@udel.edu; jf@udel.edu

\section{Summary}

This Supporting Information document provides comparison of top-down and bottom-up strengths and limitations, a description of the rationale for activity-based vs. fuel -based spatial methods, the mathmethical manipulation of STEEM elements, three tables and five figures.

\footnotetext{
*Phone: (302) 831-0768; fax: (302) 831-3668; email: jcorbett@udel.edu. Chengfeng Wang is currently an Air Pollution Specialist with the Planning and Technical Support of the California Air Resources Board (as of April 2006).
} 


\section{Strengths and Limitations of Top-down v. Bottom-up Approaches}

A top-down approach is quicker, demands relatively fewer resources than a bottom-up approach (1).

Top-down inventories can be improved by updating the global inventories and/or the spatial/temporal proxy of the ship emissions intensity. A top-down approach can produce both global and regional ship emission inventories, while existing bottom-up approaches to produce global-scale emissions inventories require a network model like STEEM.

Accuracy of top-down emissions totals is limited by uncertainty in global estimates and representative bias of spatial proxies limits the accuracy of emissions assignment (spatial precision). Differences exist among various global ship emission inventories (2-5). Recent activity-based energy consumption and emissions roughly doubled the results of earlier studies (3); uncertainties include the marine engine load factor, time in operation, and fuel consumption rates, which vary by ship type, size, age, fuel type, and market situation $(2,4)$. Spatially, both ICOADS and AMVER rely on voluntary non-random reporting, making both statistically and spatially biased (1).

Although bottom-up approaches can be more precise, large-scale bottom-up inventories also are uncertain because they estimate engine workload, ship speed, and most importantly, the locations of the routes determining the spatial distribution of emissions. The quality of regional annual inventories in bottom-up approaches is also limited when selected periods within a calendar year studied are extrapolated to represent annual totals (6-8).

Bottom-up approaches have also been limited to smaller scale emissions inventories due to the significant efforts associated with routing. Moreover, because they often use straight lines as routes between ports, they may overestimate ship emissions, as straight lines on a map usually are not the shortest path between two points on the globe. As such, locations of emissions may not be assigned correctly at larger scales.

\section{Rationale for Activity-based vs. Fuel-based Spatial Methods}

Although emissions estimates are related to the energy used by ships, recent studies call into question the validity of relying on the statistics of marine fuel sales (2, 9). Best practices of estimating emissions 
from transportation overall, and marine vessel emissions inventories specifically, have focused on activity-based estimation of energy and power demands from fundamental principles (2, 9). These approaches have shown that fuel allocated to international fuel statistics is insufficient to meet the estimated energy demand of international shipping. Even if marine fuel sales statistics were perfect, ships may consume fuel far from where they purchase it. At best, regional statistics provide limited insight into the spatial and temporal characteristics of ship energy consumption.

The inventory successfully applies bottom-up estimation methods, extending best-practices for commercial marine inventories to the largest spatially resolved scale so far, and the STEEM model is capable of conducting similar analyses for other regions and even globally. STEEM achieves many of the goals of nonroad marine modeling efforts, such as the U.S. EPA Mobile Vehicle Emissions Simulator (MOVES); see http://www.epa.gov/otaq/ngm.htm for MOVES information. STEEM helps advance MOVES current design in two important ways: 1) our approach produces spatial and temporal assignment of emissions in GIS; and 2) our model considers individual vessel movements, rather than binning vessels of similar type. (Similar to binning by MOVES, our model applies emissions factor and engine activity assumptions by vessel type, but considers installed power, routing, and speed individually.)

On a large regional scale, the most probable navigation routes are great-circle (i.e., radius) routes between transoceanic origins and destinations, adjusted where prohibited by land, ice, or depth; the Lloyds and Entec work was more regional (not transoceanic) and generally followed straight-line routes. However, near coastlines shipping lanes are defined by navigable depth, and legal or policy prohibitions, such as hazardous cargoes or marine preheated areas. Significant activity follows the western coastline of North America; emissions from ships carrying foreign cargo within the 200 nautical miles coastal areas of the United States estimated by the STEEM are about five times of the results estimated by Corbett and Fischbeck using cargo as a proxy (10). STEEM is superior to the method used by Corbett and Fischbeck and is more accurate, consistent with the uncertainty discussion 
in the earlier paper and with the upward correction of more accurate work for the Northwest, United States also published previously in ES\&T (11).

We conclude that STEEM is superior to existing approaches in five aspects: (1) the spatial location of ship traffic derived from the spatial proxy of shipping activities is empirical not speculative; (2) it uses regionally accurate historical shipping activities data, instead of primarily relying on statistics of the world fleet and its operation profiles; (3) the model is capable of producing large scale analyses of shipping characteristics and impacts (e.g., energy use and emissions inventories presented here, and other characteristics such as momentum potential for ship-whale encounters) by using automated VBA and Python scripts within the GIS platform for some repetitive work ; (4) inventories can be updated or forecast with current shipping activities and ship attributes data sets while reusing the waterway network because the structure of the observed shipping lanes are stable over many years; and (5) results from this model are more accurate than the top-down approach using ICOADS as spatial proxy and even more accurate than regional/port studies by capturing transit traffic.

\section{Mathmetical Manipulation of STEEM Elements}

Assume there are $\boldsymbol{m}$ segments and $\boldsymbol{n}$ routes in the empirical waterway network, the many-to-many relationships can be denoted as matrix $\boldsymbol{A}$.

$$
A=\begin{array}{ccccc}
b_{1,1} & b_{1,2} & b_{1,3} & \cdots & b_{1, n} \\
b_{2,1} & b_{2,2} & b_{2,3} & \cdots & b_{2, n} \\
b_{3,1} & b_{3,2} & b_{3,3} & \cdots & b_{3, n} \\
\vdots & \vdots & \vdots & \vdots & \vdots \\
b_{m, 1} & b_{m, 2} & b_{m, 3} & \cdots & b_{m, n}
\end{array}
$$

Where, $\boldsymbol{b}_{\boldsymbol{m}, \boldsymbol{n}}$ is a binary variable that shows whether segment $\boldsymbol{m}$ is part of route $\boldsymbol{n}$ (value of " 0 " if no, "1" if yes).

The actual number of trips on each route in any temporal period, where trips are defined as a one-way movement on one route, can be derived from shipping activities data set. The relationships between routes and trips can be denoted as matrix $\boldsymbol{B}$. 


$$
\begin{array}{r}
t_{1} \\
t_{2} \\
B=t_{3} \\
\vdots \\
t_{n}
\end{array}
$$

Where, $\boldsymbol{t}_{\boldsymbol{n}}$ is the number of trips on route $\boldsymbol{n}$ within one period.

Depending on need and data availability, we can either assume ships are identical (as one group or in subsets by vessel type, fuel properties, etc.) or incorporate individual ship characteristics into the model. The number of trips or the indicator of traffic volume weighted by ship attributes on each segment can be denoted as matrix $\boldsymbol{C}$.

$$
C=A \times B=\begin{gathered}
v_{1} \\
v_{2} \\
v_{3} \\
\vdots \\
v_{m}
\end{gathered}
$$

Where, $\boldsymbol{v}_{\boldsymbol{m}}$ is the number of trips or the indicator of traffic volume of segment $\boldsymbol{m}$ in one period.

To estimate fuel use and air emissions out of port areas, we assume ships travel at a typical cruising speed, which appears true in most cases. Fuel use and air emissions from individual trips can be estimated with current best-practice models based on route distance, ship characteristics, and ship operating profile. Total emissions $\boldsymbol{e}_{\boldsymbol{n}}$ on route $\boldsymbol{n}$ in one period in which there were $\boldsymbol{t}_{\boldsymbol{n}}$ trips can be estimated by equation (4), and fuel use $f_{n}$ can be estimated by equation (5).

$$
\begin{aligned}
& e_{n}=\sum_{i=1}^{t_{n}} f\left(d_{n}, s_{i}, m_{i}, a_{i}, l_{m}, l_{a}, e_{p} \cdots\right) \\
& f_{n}=\sum_{i=1}^{t_{n}} f\left(d_{n}, s_{i}, m_{i}, a_{i}, l_{m}, l_{a}, \operatorname{sfoc}_{f} \cdots\right)
\end{aligned}
$$

Where, $\boldsymbol{d}_{\boldsymbol{n}}$ is the length of route $\boldsymbol{n}, \boldsymbol{s}$ is vessel speed, $\boldsymbol{m}$ is main engine power, $\boldsymbol{a}$ is auxiliary engine power, $\boldsymbol{l}_{\boldsymbol{m}}$ and $\boldsymbol{l}_{\boldsymbol{a}}$ are load factors for main and auxiliary engines, and $\boldsymbol{e}_{\boldsymbol{p}}$ represents emission factor for pollutant $\boldsymbol{p} ; \boldsymbol{s f o c}$ in equation (5) represents specific fuel oil consumption (energy rate factor) for fuel type $f$. Equations (4) and (5) denote that total emissions $\boldsymbol{e}_{\boldsymbol{n}}$ or fuel use $\boldsymbol{f}_{\boldsymbol{n}}$ on route $\boldsymbol{n}$ in one period is a 
function of the length of route, the characteristics of the ships on that route, the operating profile of the ships, and other variables concerned like the quality of fuel, etc. Where vessel-specific estimates are not required, average vessel values can be assigned by vessel type (e.g., tankers, containerized vessels, bulk carriers) to estimate energy and emissions by route.

Emissions or energy from each route can be denoted as matrix $\boldsymbol{D}$.

$$
\begin{gathered}
e_{1} \\
e_{2} \\
e_{3} \\
\vdots \\
e_{n}
\end{gathered}
$$

Fuel use and emissions per unit of length are determined by dividing the total emissions on one route by the length of that route, which is the sum of the lengths of all segments of the route. The length of each segment can be obtained by GIS tools and can be detonated as matrix $\boldsymbol{E}$.

$$
\begin{array}{r}
l_{1} \\
l_{2} \\
l_{3} \\
\vdots \\
l_{m}
\end{array}
$$

Where, $\boldsymbol{l}_{\boldsymbol{m}}$ is the length of segment $\boldsymbol{m}$.

The distance of each route can be determined by multiplying the transposition of matrix $\boldsymbol{A}$ with matrix $\boldsymbol{E}$ and is denoted as matrix $\boldsymbol{F}$.

$$
F=A^{\prime} \times E=\begin{gathered}
d_{1} \\
d_{2} \\
d_{3} \\
\vdots \\
d_{n}
\end{gathered}
$$

Where, $\boldsymbol{A}^{\prime}$ is the transposition of matrix $\boldsymbol{A}$, and $\boldsymbol{d}_{\boldsymbol{n}}$ is the distance of route $\boldsymbol{n}$.

Energy and emissions per unit of length for route $\boldsymbol{n}$ can be determined by equation (8) and can be denoted as $\boldsymbol{u}_{n}$. 
$u_{n}=\frac{e_{n}}{d_{n}}$

Enery and emissions per unit of length for all routes are denoted as matrix $\boldsymbol{G}$.

$$
G=\begin{gathered}
u_{1} \\
u_{2} \\
u_{3} \\
\vdots \\
u_{n}
\end{gathered}
$$

Total energy or emissions from each segment within one period can be obtained by summing up the calculations from all trips on that segment during that period. Energy or emissions per unit of length for all segments are denoted as matrix $\boldsymbol{H}$.

$$
\begin{aligned}
& h_{1} \\
& h_{2} \\
& H=A \times G=h_{3} \\
& \text { ! } \\
& h_{m}
\end{aligned}
$$

Where, $\boldsymbol{h}_{\boldsymbol{m}}$ is energy or emissions per unit of length for segment $\boldsymbol{m} . \boldsymbol{h}_{\boldsymbol{m}}$ indicates the distribution of emissions over the waterway network.

Total energy or emissions for segment $\boldsymbol{m}$ can be calculated by equation (12) and can be denoted as $\boldsymbol{k}_{\boldsymbol{m}}$.

$$
k_{m}=l_{m} \times h_{m}
$$

Total energy or emissions for each segment can be further allocated to each grid to produce spatiallyresolved inventories per gridded area if the segment was established as a polygon.

Table SI1. Relationships among ship NRT, GRT and main engine installed power

NRT and GRT $^{1} \quad$ GRT and Power ${ }^{2}$




\begin{tabular}{lllllll}
\hline \multirow{2}{*}{ Ship Type } & $\begin{array}{l}\text { Number of } \\
\text { Samples }\end{array}$ & $\mathrm{y}$ as GRT, $\mathrm{x}$ As NRT & $\mathrm{R}^{2}$ & $\begin{array}{l}\text { Number of } \\
\text { Samples }\end{array}$ & $\mathrm{y}$ as power, $\mathrm{x} \mathrm{As} \mathrm{GRT}$ & $\mathrm{R}^{2}$ \\
\hline Container ship & 1,372 & $\mathrm{y}=2.9594 \mathrm{x}^{0.965}$ & 0.94 & 1,149 & $\mathrm{y}=2.5008 \mathrm{x}^{0.8801}$ & 0.92 \\
Tanker & 2,814 & $\mathrm{y}=4.3031 \mathrm{x}^{0.9172}$ & 0.95 & 1,817 & $\mathrm{y}=18.189 \mathrm{x}^{0.6093}$ & 0.92 \\
General Cargo & 3,881 & $\mathrm{y}=1.9999 \mathrm{x}^{0.9992}$ & 0.98 & 2,244 & $\mathrm{y}=5.3799 \mathrm{x}^{0.7633}$ & 0.86 \\
Bulk Carrier & 4,820 & $\mathrm{y}=2.4517 \mathrm{x}^{0.9619}$ & 0.98 & 1,700 & $\mathrm{y}=66.728 \mathrm{x}^{0.4826}$ & 0.74 \\
Reefer & 512 & $\mathrm{y}=4.6369 \mathrm{x}^{0.8976}$ & 0.87 & 227 & $\mathrm{y}=1.2462 \mathrm{x}^{0.9783}$ & 0.91 \\
RO-RO & 848 & $\mathrm{y}=3.056 \mathrm{x}^{0.987}$ & 0.93 & 965 & $\mathrm{y}=692.09 \mathrm{x}^{0.2863}$ & 0.83 \\
Passenger & 459 & $\mathrm{y}=1.6034 \mathrm{x}^{1.0258}$ & 0.99 & 299 & $\mathrm{y}=0.6379 \mathrm{x}+1411.5$ & 0.95 \\
Fishing & 227 & $\mathrm{y}=3.1075 \mathrm{x}-149.78$ & 0.96 & 3,440 & $\mathrm{y}=19.266 \mathrm{x}^{0.6658}$ & 0.69 \\
Miscellaneous & 5,190 & $\mathrm{y}=2.8151 \mathrm{x}^{0.9467}$ & 0.91 & 3,951 & $\mathrm{y}=77.806 \mathrm{x}^{0.5283}$ & 0.51
\end{tabular}

Notes: 1. Samples are unique NRT and GRT pairs in USACE Entrances and Clearances data set 19972003 (12); 2. Samples are ships with GRT and main engine total installed power data in Lloyds Register CD-ROM 2004 (13); 3. The regression type with higher $\mathrm{R}^{2}$ between linear and power regression is chosen; 4. RO-RO is an industry acronym for Roll-on/Roll-off vessel.

Table SI2. Average cruise speed by ship type

\begin{tabular}{lllll}
\hline Ship Type & $\begin{array}{l}\text { Number of } \\
\text { Samples }\end{array}$ & $\begin{array}{l}\text { Average } \\
\text { Speed (knots) }\end{array}$ & $\begin{array}{l}\text { Lloyds Register } \\
\text { Study }\end{array}$ & $\begin{array}{l}\text { Entec Study } \\
\text { (knots) }\end{array}$ \\
\hline Container Ship & 2,596 & 19.9 & 20.0 & 19.0 \\
Tanker & 7,082 & 13.2 & 15.0 & 14.4 \\
General Cargo & 9,308 & 12.3 & 14.0 & 12.0 \\
Bulk Carrier & 4,464 & 14.1 & 14.0 & 13.6 \\
Reefer & 850 & 16.4 & 20.0 & 17.0 \\
RO-RO & 2,996 & 16.9 & 18.0 & 15.0 \\
Passenger & 1,825 & 22.4 & 20.0 & 21.0 \\
Fishing & 8,199 & 11.7 & 13.0 & 13.6 \\
Miscellaneous & 10,116 & 12.7 & 11.0 & 12.0 \\
\hline
\end{tabular}

Notes: 1. Samples are ships with service speed in Lloyds Register CD-ROM (13).

Table SI3. Summary of engine power and at-sea load profile 


\begin{tabular}{llllll}
\hline Vessel Type & $\begin{array}{l}\text { Average } \\
(\mathrm{kW})\end{array}$ & ME & Power & $\begin{array}{l}\text { At-sea ME } \\
(\% \mathrm{MCR})\end{array}$ & $\begin{array}{l}\text { load } \\
\text { AE } \\
(\mathrm{kW})\end{array}$ \\
\hline Bulk Carrier & 7,954 & $75 \%$ & 1,169 & $17 \%$ \\
Container Ship & 30,885 & $80 \%$ & 5,746 & $13 \%$ \\
General Cargo & 9,331 & $80 \%$ & 1,777 & $17 \%$ \\
Passenger/Cruise & 39,563 & $55 \%$ & 39,563 & $25 \%$ \\
Reefer & 9,567 & $80 \%$ & 1,300 & $20 \%$ \\
RO-RO & 10,696 & $80 \%$ & 2,156 & $15 \%$ \\
Tanker & 9,409 & $75 \%$ & 1,985 & $13 \%$ \\
Miscellaneous & 6,252 & $70 \%$ & 1,680 & $17 \%$ \\
\hline
\end{tabular}
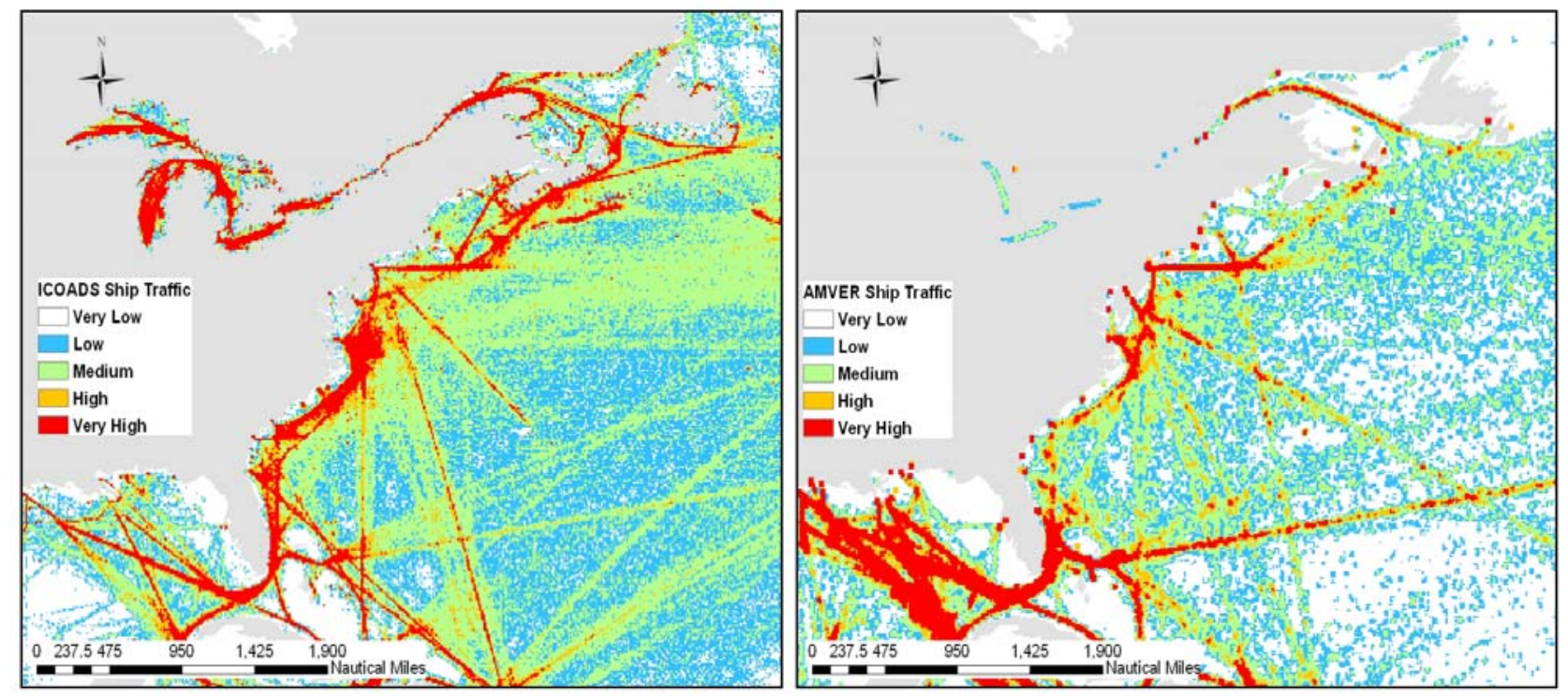

Figure SI1. Comparison of shipping lanes derived from ICOADS and AMVER. 


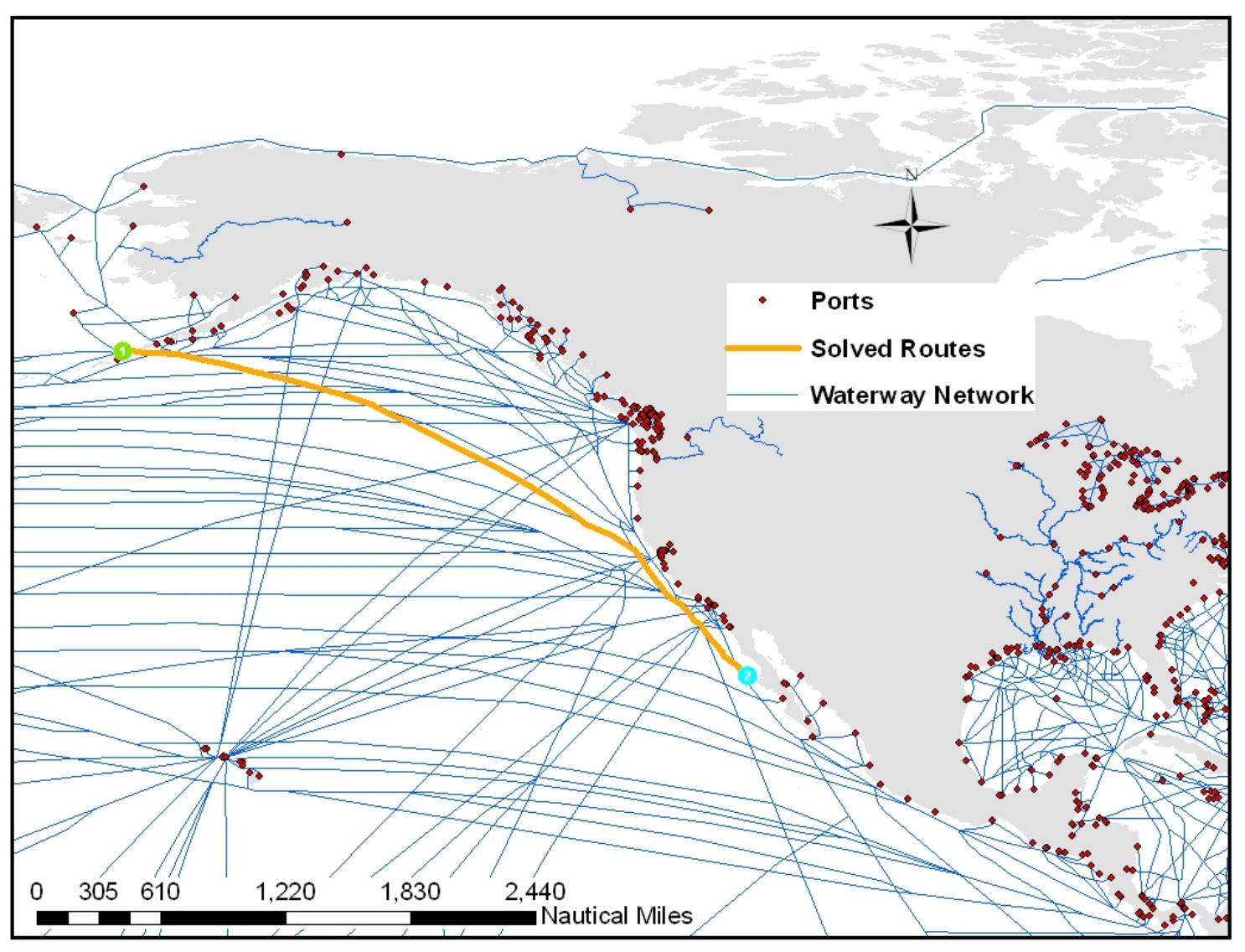

Figure SI2. Illustration of the empirical waterway network and a sample of solved routes.

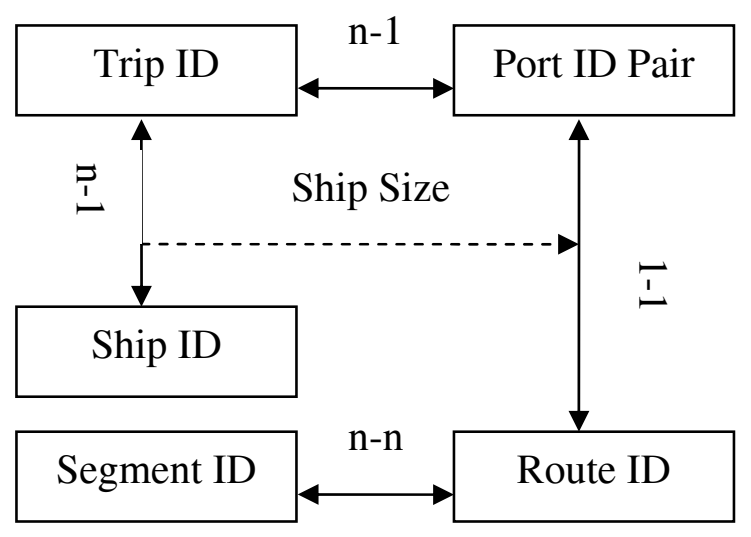

Figure SI3. Illustration of relationships of the elements of STEEM. 


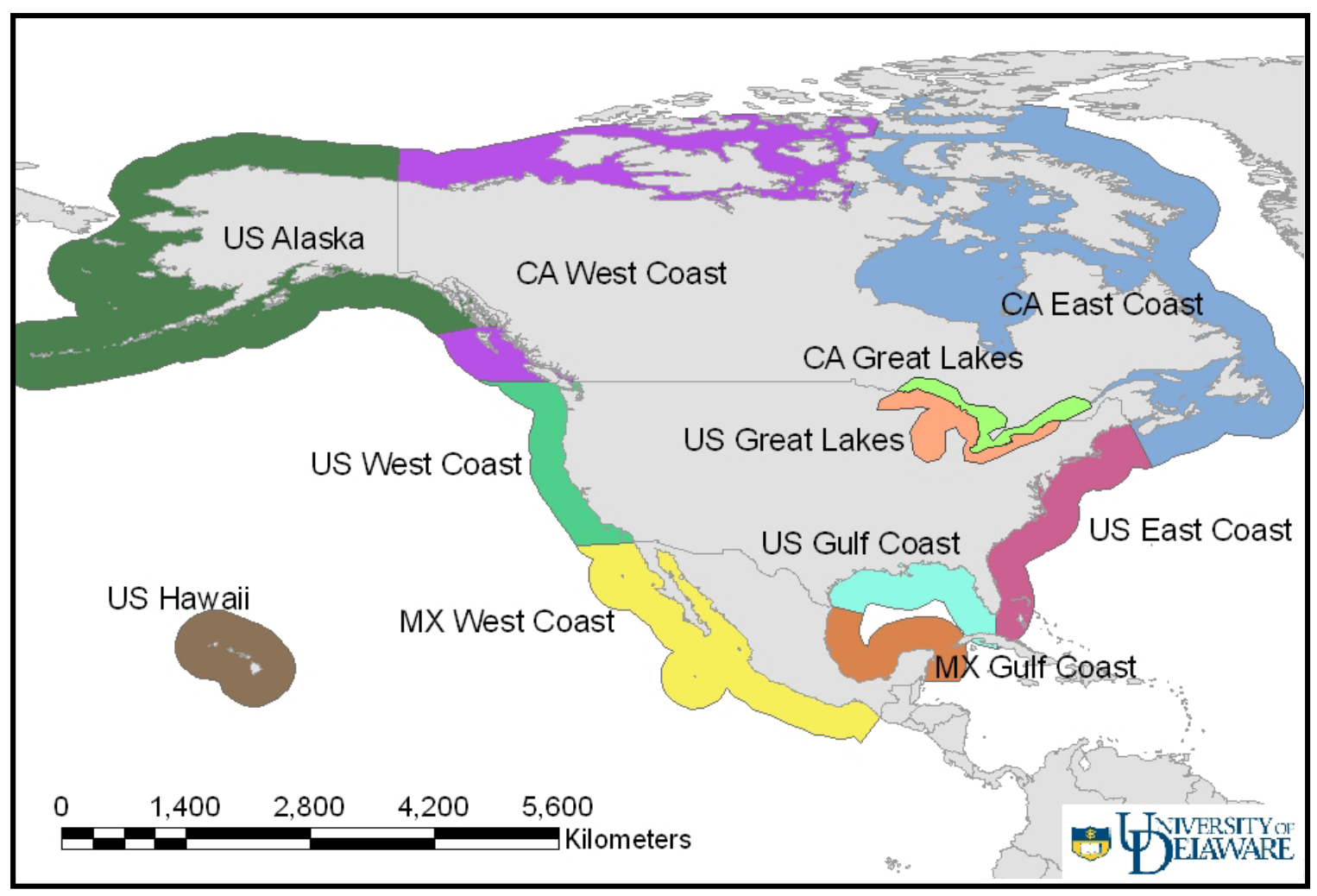

Figure SI4. Illustration of coastal areas of North America.

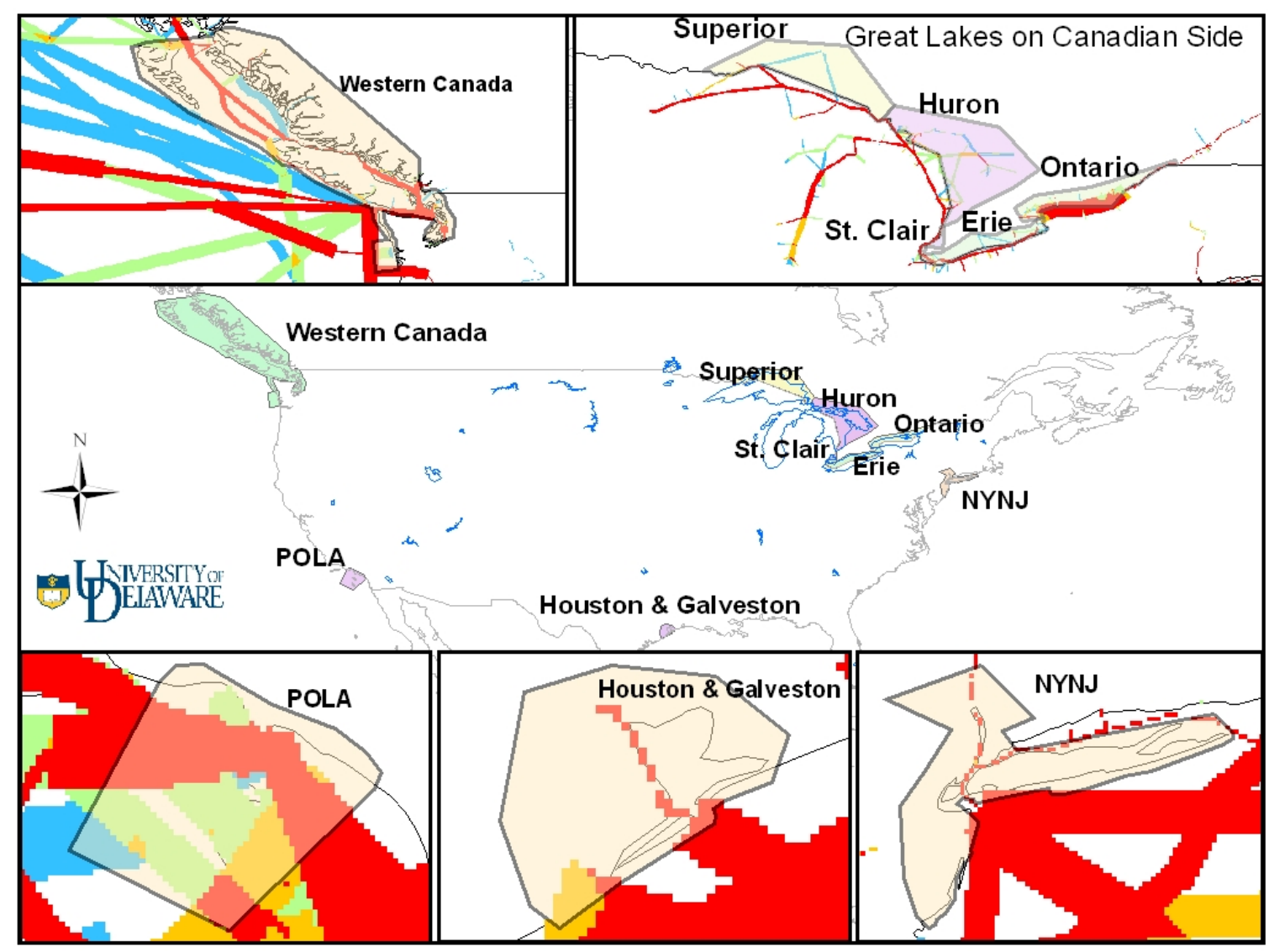


Figure SI5. Illustration of domains of regional/port emission inventories studies. The Great Lakes

include the lakes and connecting waters within the Canadian boundary (14); "Western Canada" represents the coastal areas in British Columbia (B.C.) outside of the Greater Vancouver Regional District (GVRD) and Fraser Valley Regional District (FVRD), and a portion of Washington State, as defined in the Levelton report (15); The Port of Los Angeles (POLA), Houston \& Galveston area, and the Port of New York and New Jersey (NYNJ) are the areas defined by the Starcrest Consulting Group, LLC in its port-wide air emissions inventory reports (16-18).

\section{References:}

1. Wang, C., J.J. Corbett, and J. Firestone. Adapting Bottom-up Methods to Top-down Spatially Resolved Ship Emissions Inventories. in Transportation Research Board of the National Academies 85th Annual Meeting. 2006. Washington D.C.

2. Corbett, J.J. and H.W. Koehler, Considering alternative input parameters in an activity-based ship fuel consumption and emissions model: Reply to comment by Øyvind Endresen et al. on " 'Updated emissions from ocean shipping'. Journal of Geophysical Research, 2004. 109(D23303).

3. Corbett, J.J. and H.W. Koehler, Updated Emissions from Ocean Shipping. Journal of Geophysical Research - Atmospheres, 2003. 108(D20): p. 4650-4666.

4. $\quad$ Endresen, $\varnothing$., et al., Substantiation of a lower estimate for the bunker inventory: Comment on "Updated emissions from ocean shipping"' by James J. Corbett and Horst W. Koehler. Journal of Geophysical Research, 2004. 109(D23302).

5. $\quad$ Endresen, Ø., et al., Emission From International Sea Transportation and Environmental Impact. Journal of Geophysical Research - Atmospheres, 2003. 108(10.1029/2002JD002898).

6. Lloyd's Register, Marine Exhaust Emissions Quantification Study - Mediterranean Sea. 1999.

7. Lloyd's Register and International Maritime Organization, Marine Exhaust Emission Quantification Study - Baltic Sea, in MEPC 45/INF.7. 1998.

8. Commission of the European Communities and Entec UK Limited, Quantification of Emissions from Ships Associated with Ship Movements between Ports in the European Community. 2002, European Commission.

9. Corbett, J.J. and H.W. Koehler, Updated Emissions from Ocean Shipping. Journal of Geophysical Research, 2003. 108(D20): p. 4650.

10. Corbett, J.J. and P.S. Fischbeck, Emissions from Waterborne Commerce Vessels in United States Continental and Inland Waterways. Environmental Science and Technology, 2000. 34(15): p. 3254-3260.

11. Corbett, J.J., Emissions from Ships in the Northwestern United States. Environmental Science \& Technology, 2002. 36(6): p. 1299-1306.

12. USACE, Vessel Entrances and Clearances. 2004, Waterborne Commerce Statistics Center, U.S. Army Corps of Engineers.

13. Lloyd's Register - Fairplay, Lloyd's Register of Ships on CD ROM. 2004.

14. Levelton Consultants Ltd., Marine Emission Inventory Study Eastern Canada and Great Lakes Interim Report 4: Gridding Results. 2006, Prepared for: Transportation Development Centre Transport Canada.

15. Levelton Engineering Ltd., Marine Vessel Air Emissions in B.C. and Washington State outside the GVRD and FVRD for the Year 2000. 2002. 
16. Aldrete, G., et al., Port-wide Baseline Air Emissions Inventory Prepared for Port of Los Angeles. 2004, Starcrest Consulting Group, LLC.

17. Anderson, B. and S. Wells, The New York, Northern New Jersey, Long Island Nonattainment Area Commercial Marine Vessel Emissions Inventory. 2003, Starcrest Consulting Group, LLC.

18. Anderson, B.E. and J.L. Ray, Houston-Galveston Area Vessel Emissions Inventory. 2002, Starcrest Consulting Group, LLC. 